\title{
Compression Behavior of Form Block Walls Corresponding to the Strength of Block and Grout Concrete
}

\author{
S. Y. Seo ${ }^{1), *}$, S. M. Jeon ${ }^{1)}$, K. T. Kim²), M. Kuroki ${ }^{3)}$, and K. Kikuchi ${ }^{3)}$ \\ (Received July 8, 2014, Accepted October 28, 2014, Published online November 25, 2014)
}

\begin{abstract}
This study aimed to present a reinforced concrete block system that reduces the flange thickness of the existing form block used in new buildings and optimizes the web form, and can thus capable of being used in the seismic retrofit of new and existing buildings. By conducting a compression test and finite element analysis based on the block and grouted concrete strength, it attempted to determine the compression capacity of the form block that can be used in new construction and seismic retrofit. As a result, the comparison of the strength equation from Architectural Institute of Japan to the prism compression test showed that the mortar coefficient of 0.55 was suitable instead of 0.75 recommended in the equation. The stress-strain relation of the block was proposed as a bi-linear model based on the compression test result of the single form block. Using the proposed model, finite element analysis was conducted on the prism specimens, and it was shown that the proposed model predicted the compression behavior of the form block appropriately.
\end{abstract}

Keywords: form block, prism test, finite element analysis, grout concrete, mortar coefficient, compression behavior.

\section{Introduction}

In the recent seismic retrofit of school buildings in South Korea, whose construction is susceptible to damage from earthquakes, the most widely used retrofit method for frame buildings is installing a damper in the openings such as windows in tandem with the expansion of infill walls. Infill walls are usually cast-in-place concrete, but another possible construction method involves the use of reinforced block walls.

Compared to cast-in-place concrete, reinforced block walls have a somewhat lower structural capacity but offer excellent constructability, and thus, if they satisfy the required capacity, they can be recommended for use in a seismicstrengthening method. Usually, blocks used as reinforced block walls make it difficult to fill the hollow block zones with a sufficient amount of grouted concrete. Furthermore, their hollow areas are relatively small, and as such, the amount of grouted concrete is also small. In addition, bar arranging in construction is difficult, and thus, they provide little structural integrity. If the amount of grouted concrete increases, the blocks become thinner, so that when casting,

\footnotetext{
${ }^{1)}$ Department of Architectural Engineering, Korea National University of Transportation, Chungju, Korea. *Corresponding Author; E-mail: syseo@ut.ac.kr

${ }^{2)}$ B\&K Construction Technology, Chungju, Korea.

${ }^{3)}$ Department of Architecture and Mechatronics, Oita University, Oita, Japan.

Copyright $($ The Author(s) 2014. This article is published with open access at Springerlink.com
}

their resistance to lateral pressure decreases, and they can be easily broken during delivery or construction. Therefore, the size of the hollow zones should be determined based on a comprehensive review of the constructability and strength of the blocks. The form block used for a new construction has wider hollow zones than the existing blocks. In other words, it increases the volumetric ratio of grouted concrete, which increases its strength and thus improves the structural capacity of the wall after the completion of the construction.

Accordingly, this study aimed to present a reinforced concrete block system that reduces the flange thickness of the existing form block used in new buildings and optimizes the web form, and can thus capable of being used in the seismic retrofit of new and existing buildings. By conducting a compression test and finite element analysis based on the block and grouted concrete strength, it attempted to determine the compression capacity of the form block that can be used in new construction and seismic retrofit.

\section{Compression Behavior of the Reinforced Form Block Wall}

\subsection{Construction Process of the Reinforced Form Block Wall}

The construction process of reinforced form-block-walls follows the Standard Specifications for architectural construction (2013), where the vertical mortar joint of the block wall is set as the continuous joint to reinforce the hollow zones with bar and grouted concrete. In the case of the infill wall, as a seismic retrofit method for a building, as shown in Fig. 1, the vertical bar is fixed onto the base plate and the block corners, 


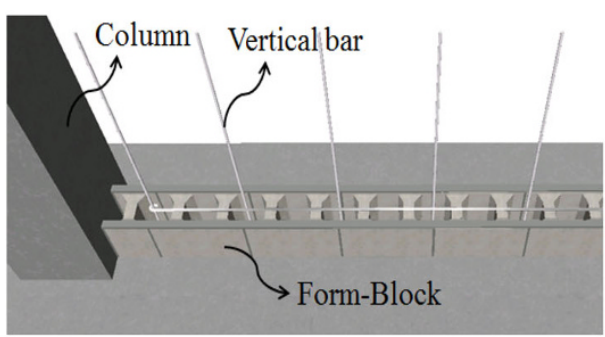

(a) Settlement of vertical bars

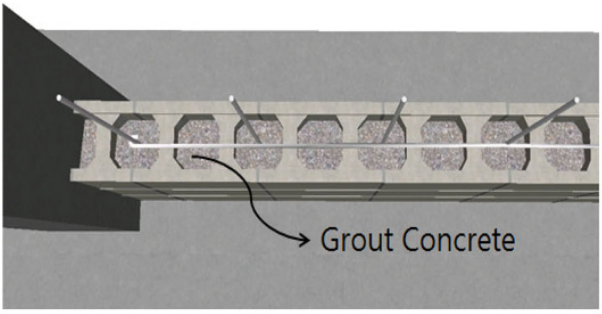

(c) Casting grout concrete

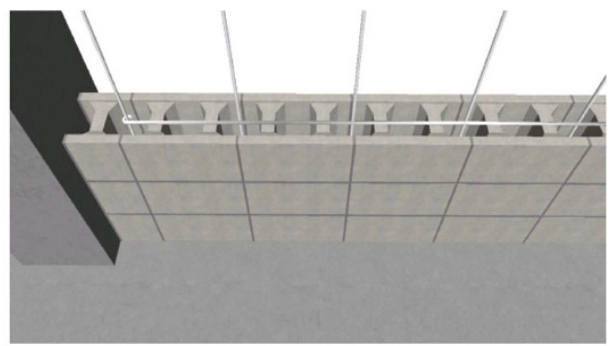

(b) Staking blocks

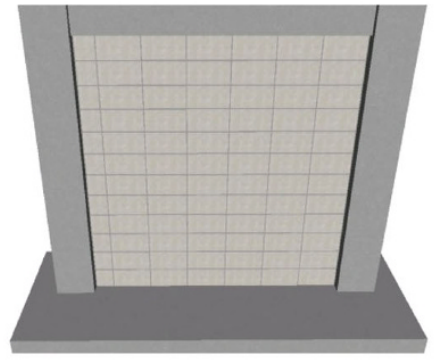

(d) Completion of wall construction

Fig. 1 Construction process of form-block-wall.

and the other standard parts are first constructed, and then the horizontal bar is arranged and blocks are stacked on top of the mortar. On top of the walls are gaps for grouted concrete, which are finished using non-shrinking mortar.

For the design of the reinforced form block walls, the structural capacity of the walls against compression and shear force should be determined. In particular, the compression capacity of the walls whose hollow block zones are filled with grouted concrete allows the walls to function as braces on frames with the compression strut under the horizontal load, and therefore becomes the most important structural capacity. Therefore, for the design of the new construction of the form block and for seismic retrofit, it is essential to predict the appropriate compression structure of block walls.

\subsection{Previous Researches}

Masonry walls and concrete blocks have long been used in construction, and much research has been conducted on them in other countries. Recently, Jonaitis and Zavalis (2013) conducted a test to determine the compression behavior of an empty concrete block and of another block filled with grouted concrete. A fracture was found on the mortar joint of the empty concrete block, and as such, an increase in compression stress caused lateral deformation. Furthermore, it was discovered that the concrete block filled with grouted concrete showed a compression behavior similar to that of cast-in-place concrete. Shing et al. (1989) evaluated the fracture mechanism, ductility, and energy dissipation capacity of shear block walls through the cyclic loading test to determine their nonlinear behavior. Based on the test results, he reported that through seismic retrofit by using shear block walls, a resistance capacity to shear and ductility could be acquired to some degree. Zhai and Stewart (2010) presented a new theoretical equation with the material strength, types of live load, the ratio of dead load to live load, and the combination of the eccentricity and concentric load as parameters to establish the safety guideline for reinforced block walls in China, and verified the appropriateness of the equation through tests. In Japan, form blocks are widely used in new construction projects where only grouted concrete used to fill the hollow zones inside the blocks would be considered to provide sufficient strength, and blocks would be considered to function only as a form (Architecture Institute of Japan 2006).

As opposed to Japan, in South Korea, three-story or lower buildings are constructed with unreinforced block, and those higher than three-story buildings are usually frame building or wall-type apartment. Therefore, few new buildings are constructed with form block. Accordingly, little research has been conducted on the form block, and some studies focused on its use for the seismic retrofit of frame type building. Yun et al. (2005) conducted an experiment on the use of blocks manufactured with recycled aggregate as infill walls, which showed that if block walls made with recycled aggregate are used in the construction of infill walls, the initial stiffness and shear strength can be improved. Compared to the castin-place infill walls, however, the reinforcement with block walls made with recycled aggregate is less effective, and due to constructability issues, it was shown to be difficult to acquire a reliable reinforcement effect. Kim et al. (2004) established a concept of a reinforced masonry wall with stacked hollow form blocks with a bar arranged inside and filled with concrete, and conducted a test on the wall reinforced with form block walls in a concrete frame. The test results showed that such a concept could produce an excellent seismic retrofit effect, and when reviewed based on the equation for the shear strength of reinforced masonry walls in Japan Code, the shear strength of the wall was found to be relatively under-evaluated. 
As for the design of masonry wall construction in the Korean Building Code (2009), the cement-to-sand ratio (1:2.0-3.0) for bearing mortar is codified instead of the design strength; it is known that the value is for developing the compression strength of 30-40 Mpa. In the case of the grout, as with the bearing mortar, cement-to-sand ratio is used, but the minimum strength is set to be 1.3 times more than the compression strength of the masonry unit. If it is satisfied, after 28-day curing, the compression strength of the masonry can be decided through the prism test or unit strength test of block.

In International Building Code (2012) of USA, also, the strength of bearing mortar is decided by the mix ratio of cement-to-sand. The grout design also is achieved by the cement-to-sand mix ratio and its minimum strength and slump flow are codified. The compression strength of the grout should be over the design compression strength of masonry after 28-day curing, between 13.79 and $34.47 \mathrm{MPa}$ (in the case of the concrete block). The slump flow should be ranged from 610 to $762 \mathrm{~mm}$. As with $\mathrm{KBC}$, the compression strength of the masonry wall can be verified through either the prism test or the unit strength of masonry, and it should meet the scope of 10.34-27.58 MPa (in the case of the concrete block).

From the above, in the case of $\mathrm{KBC}$ and $\mathrm{IBC}$, if the bearing mortar and grout are mixed based on the standard, and the compression strength is over the standard strength, either the result of the prism test or that of the masonry unit strength can be used so that in the end, the strength of the form bock wall is determined by the masonry unit. When the strength of the grout, however, is lower than the masonry unit strength, neither code does not clearly identify how the strength can be calculated.

On the other hand, Japan (JASS 7), which shows considerable use of the form block, which is often used in seismic retrofit, offers equations for the compression strength, elastic module, and shear module of block walls using the material test results of the bearing mortar, grout, and masonry unit.

Seismic retrofit using blocks needs sufficient explanation of the structural capacity of the concrete-filled block walls against compression, based on which the resistance capacity against lateral force should be determined. Accordingly, this study aimed to present a design method for form block walls with optimized web and flange dimensions by considering the constructability and structural capacity and by conducting a compression test and a prism compression test on a single block as part of the research on examining the efficiency of reinforcement against compression. Furthermore, it aimed to examine an analysis method with which to predict the compression behavior of form block walls using nonlinear finite element analysis.

\section{Compression Test of the Single Form Block}

\subsection{Compression Test Layout}

As shown in Fig. 2, the size of the form block that was used in this study was $390 \times 200 \times 185 \mathrm{~mm}$. The shape and dimension of the block was decided from the consideration to improve the quality control during the production of the blocks as well as the fabrication of those at the site. Based on the concept, the center of webs was moved to litter bit upper from the horizontal center line and the end of web was enlarged to increase the rigidity of both web and flange especially at the bottom region. Finite element analyses were performed to find best dimension.

This block was developed to be used as an in-filled wall in seismic retrofit of frame structure. As a construction process shown in Fig. 1, at first, the bars for vertical continuity shall be vertically anchored in the beams and then the form blocks shall be laid on the beams. In order to have horizontal continuity, bars also shall be horizontally anchored to columns. Those bars shall be connected to other bars by lap splicing. All blocks shall be laid on bearing mortar. After laying three blocks vertically, grout concrete shall be poured into the void holding bars vertically.

The compression-test parameters of the single form block were four mixing design ratios, as shown in Table 1, and the load was applied on the specimen, as in Fig. 3, based on the compression test on the whole section of the hollow concrete block according to KS F 4002 (2011).
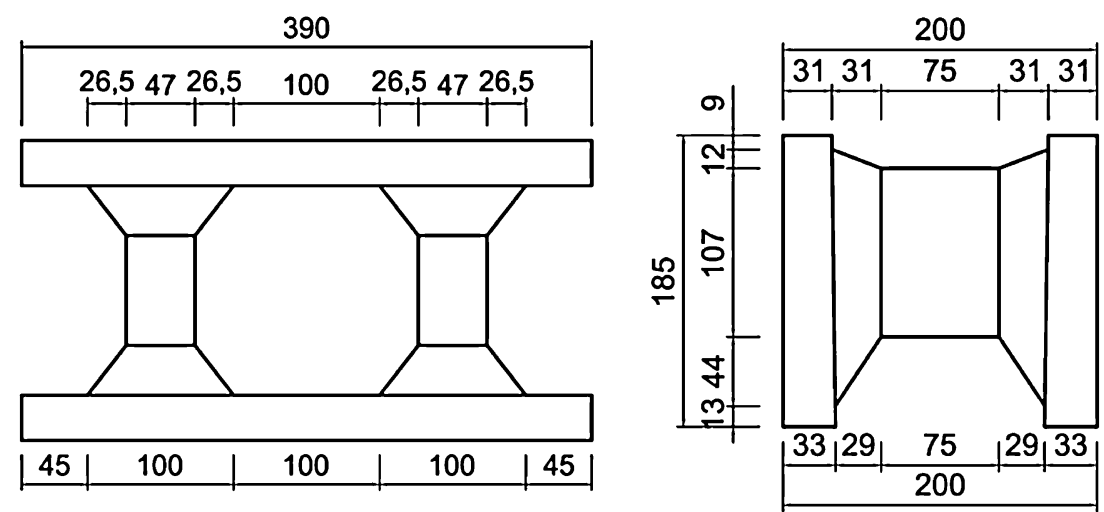

Fig. 2 Dimension of developed form-block (Unit: $\mathrm{mm}$ ). 
Table 1 Mixing design of form-block.

\begin{tabular}{c|c|c|c|c|c}
\hline Type & $\begin{array}{c}\text { Designed compressive } \\
\text { strength (MPa) }\end{array}$ & Cement (\%) & Sand (\%) & $\begin{array}{c}\text { Water (\%) } \\
\text { C:\%) }\end{array}$ \\
\hline \hline B1 & 23.0 & 12.07 & 80.45 & 7.48 & 62.11 \\
\hline B2 & 25.0 & 13.70 & 78.31 & 7.99 & 58.48 \\
\hline B3 & 34.0 & 15.48 & 77.33 & 7.19 & 46.51 \\
\hline B4 & 38.0 & 19.35 & 72.53 & 8.12 & 42.02 \\
\hline
\end{tabular}

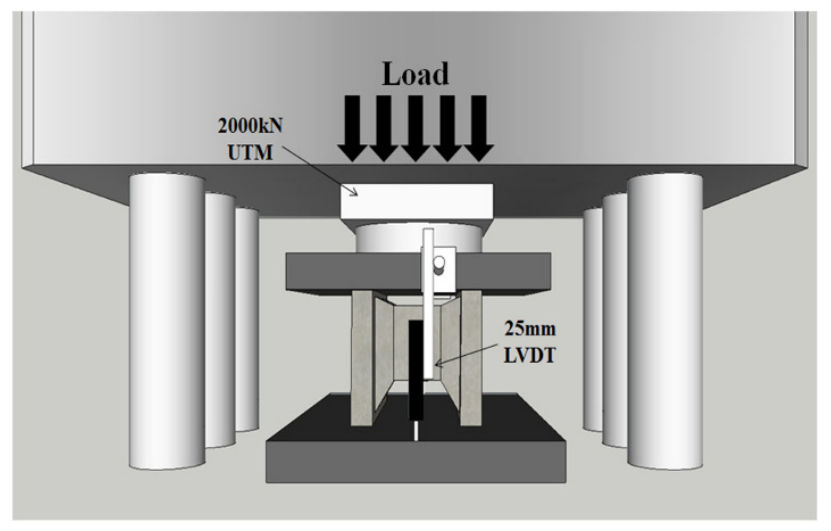

Fig. 3 Test setup for testing compressive strength of formblock.

\subsection{Compression Test Result}

Shown in Fig. 4 is the load-displacement curve measured as the result of the single form block test. It shows a linear curve initially, and the compression displacement rapidly increases at a certain point when several vertical cracks occur

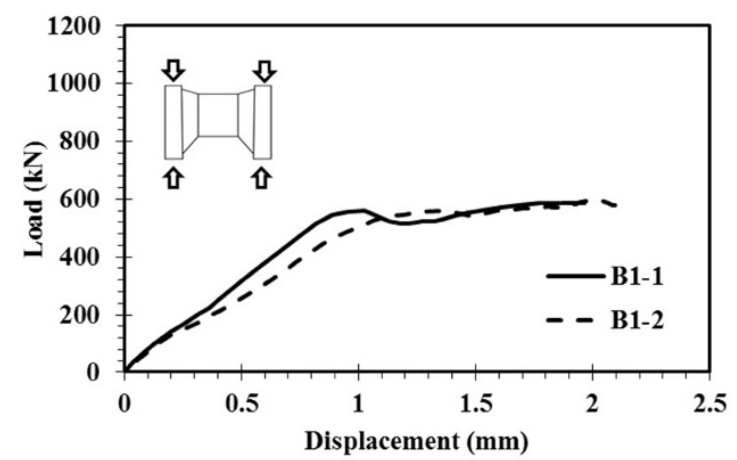

(a) B1 series

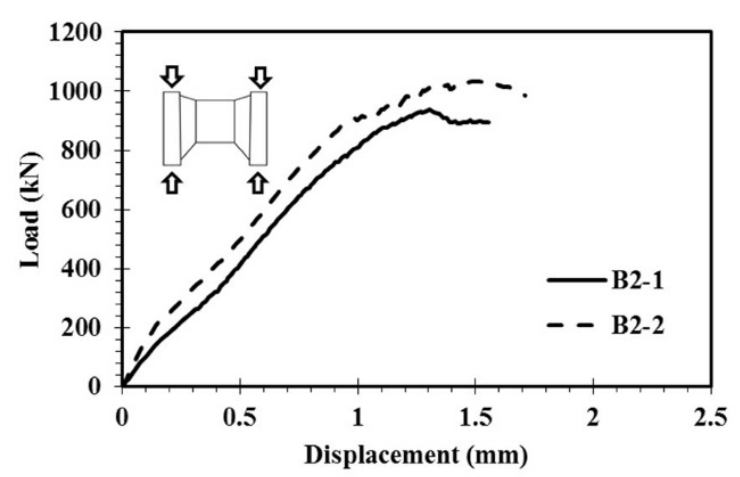

(b) B2 series on flange from top to middle, leading to the crushing failure of upper part of both flanges without any failures in the webs. This pattern was observed in most blocks. Shown in Table 2 are the stress and strain at the maximum load and the strain value at the point when the strain suddenly increases after the elastic zone showing vertical cracks on flanges. This shows that as the amount of the cement increases, the compression strength of the block also increases, exceeding the predicted design strength based on each mixing ratio $(23,25,34$, and $38 \mathrm{MPa}$ ) shown in Table 1.

Figure 5 shows the strains at both yield and ultimate state corresponding to the compression strength. The strain at ultimate state decreases corresponding to the increase of compression strength while the yield strain is constant regardless the change of that. From Fig. 6 representing the ratio $\varepsilon_{b y} / \varepsilon_{b u}$, it is found that the ratio is linearly dependent on compressive strength. The ratio can be expressed as a function of ultimate strength of block such as $0.02 f_{b u}$ (dimensionless). This means the plastic deformation decreases gradually corresponding to the increase of ultimate strength of block due to brittle behavior as shown in Fig. 7. Also, the whole average value of elastic limit

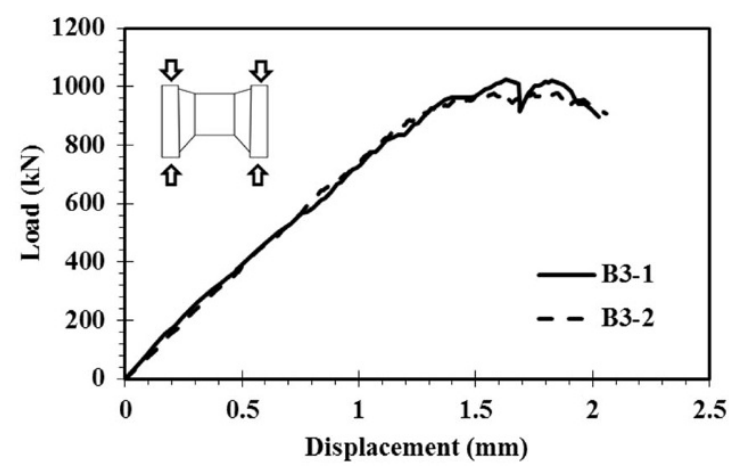

(c) B3 series

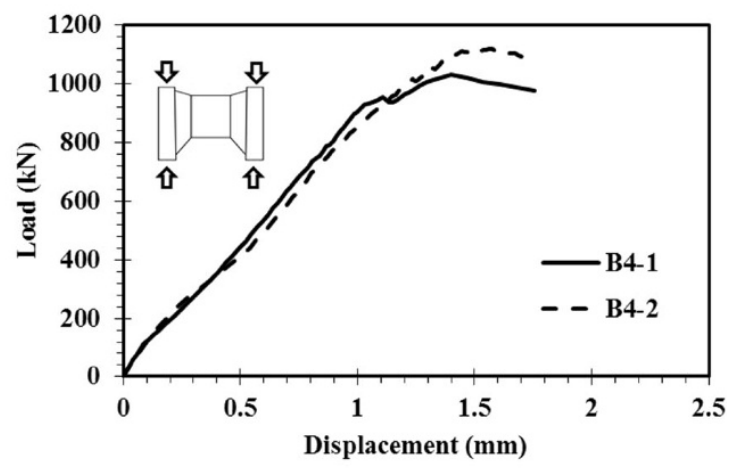

(d) B4 series

Fig. 4 Load-displacement curve of single form-block. 


\begin{tabular}{|c|c|c|c|c|c|c|c|c|}
\hline \multirow{3}{*}{$\begin{array}{l}y \\
\bar{c} \\
\tilde{y} \\
\tilde{\infty}\end{array}$} & 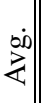 & $\mid \begin{array}{l}0 \\
0 \\
\dot{I} \\
0\end{array}$ & $\begin{array}{l}\ddot{\alpha} \\
\ddot{\gamma} \\
\dot{f}\end{array}$ & $\stackrel{\text { gे }}{-}$ & $\begin{array}{l}8 \\
\stackrel{\infty}{0} \\
0\end{array}$ & $\vec{\cong}$ & 奋 & $\begin{array}{l}\vec{\Xi} \\
\infty \\
0 \\
0\end{array}$ \\
\hline & $\underset{⿱}{\mathfrak{d}}$ & $\mid \begin{array}{l}\vec{a} \\
\stackrel{\Xi}{\Xi}\end{array}$ & $\begin{array}{l}\vec{D} \\
\infty \\
\dot{f}\end{array}$ & 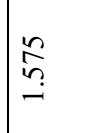 & $\stackrel{\infty}{\infty}$ & $\stackrel{g}{\stackrel{g}{m}}$ & $\stackrel{\Re}{\stackrel{0}{0}}$ & $\mid \begin{array}{l}n \\
\infty \\
0 \\
0\end{array}$ \\
\hline & $\vec{q}$ & $\mid \begin{array}{l}0 \\
\stackrel{0}{0} \\
\tilde{0} \\
0\end{array}$ & $\begin{array}{l}\hat{y} \\
\vec{F}\end{array}$ & ळे & $\stackrel{0}{\stackrel{0}{0}}$ & 总 & $\stackrel{\infty}{\infty}$ & $\frac{8}{8}$ \\
\hline \multirow{3}{*}{ 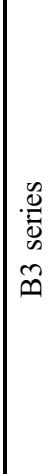 } & 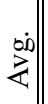 & กิ & $\frac{m}{\dot{q}}$ & $\stackrel{\infty}{-}$ & ڤे & $\stackrel{?}{\stackrel{f}{-}}$ & $\stackrel{\hat{a}}{\hat{0}}$ & 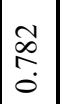 \\
\hline & 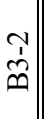 & $\frac{n}{\hat{\alpha}}$ & $\frac{\infty}{a}$ & 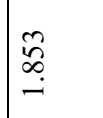 & $\stackrel{8}{-}$ & $\underset{\overbrace{}}{\tilde{I}}$ & 它 & $\begin{array}{l}\hat{0} \\
0 \\
0\end{array}$ \\
\hline & $\vec{m}$ & $\begin{array}{l}\overrightarrow{\tilde{a}} \\
\text { Oे }\end{array}$ & $\begin{array}{l}\hat{o} \\
\dot{\vec{\gamma}}\end{array}$ & 嶽 & $\stackrel{\infty}{\circ}$ & 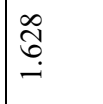 & $\begin{array}{l}\infty \\
\stackrel{\infty}{0} \\
0\end{array}$ & 文 \\
\hline \multirow{3}{*}{ 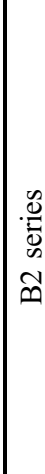 } & $\sum_{\substack{i 0 \\
\gtrless}}$ & 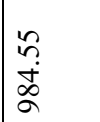 & $\begin{array}{l}\text { 年 } \\
\text { d. }\end{array}$ & $\stackrel{\sim}{n}$ & $\begin{array}{l}0 \\
0 \\
0\end{array}$ & $\stackrel{0}{\rightleftarrows}$ & $\stackrel{6}{0}$ & $\begin{array}{l}\overrightarrow{0} \\
\stackrel{0}{0}\end{array}$ \\
\hline & $\stackrel{\sim}{\widetilde{\infty}}$ & $\frac{8}{\stackrel{8}{0}}$ & $\stackrel{\Re}{\stackrel{m}{\sigma}}$ & 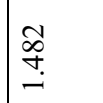 & $\begin{array}{l}0 \\
\infty \\
0\end{array}$ & 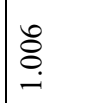 & 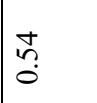 & है \\
\hline & $\overrightarrow{\stackrel{a}{m}}$ & $\begin{array}{l}\stackrel{n}{n} \\
\stackrel{n}{n}\end{array}$ & $\begin{array}{l}0 \\
\stackrel{n}{n} \\
i n\end{array}$ & $\begin{array}{l}0 \\
\stackrel{0}{n} \\
n \\
-n\end{array}$ & $\begin{array}{l}+ \\
\infty \\
0 \\
0\end{array}$ & 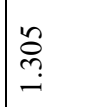 & $\vec{i}$ & $\mid \begin{array}{c}\infty \\
\tilde{\infty} \\
\infty \\
0\end{array}$ \\
\hline \multirow{3}{*}{$\begin{array}{l}\frac{y}{5} \\
\frac{0}{x} \\
x\end{array}$} & 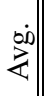 & $\begin{array}{l}\hat{\sigma} \\
\tilde{n} \\
\text { nิ }\end{array}$ & $\underset{\hat{i}}{\hat{\lambda}}$ & $\stackrel{2}{-}$ & $\stackrel{\leftrightarrow}{\leftrightarrow}$ & $\stackrel{\overbrace{}}{\cong}$ & $\underset{0}{\infty}$ & 隹 \\
\hline & $\frac{\Upsilon}{m}$ & $\begin{array}{l}\text { ते } \\
\text { ڤे }\end{array}$ & $\begin{array}{l}\vec{\sigma} \\
\stackrel{d}{d}\end{array}$ & $\begin{array}{l}0 \\
\ddot{\theta} \\
i \\
i\end{array}$ & $\stackrel{\varrho}{=}$ & $\stackrel{m}{m}$ & $\stackrel{J}{\stackrel{0}{0}}$ & 点 \\
\hline & $\frac{1}{m}$ & $\begin{array}{l}0 \\
\infty \\
\infty \\
\infty \\
\infty \\
n\end{array}$ & $\begin{array}{l}\ddot{n} \\
\ddot{n}\end{array}$ & $\mid \begin{array}{l}\infty \\
\stackrel{\infty}{\infty} \\
\stackrel{\infty}{+}\end{array}$ & $\stackrel{\vec{\sigma}}{-}$ & 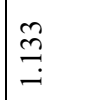 & $\overrightarrow{0}$ & $\begin{array}{l}0 \\
0 \\
0 \\
0\end{array}$ \\
\hline \multirow{2}{*}{ 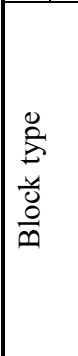 } & & 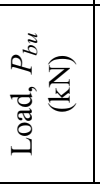 & 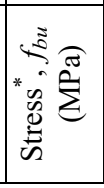 & 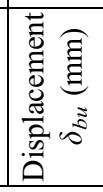 & 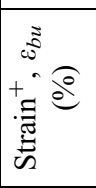 & 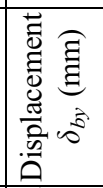 & 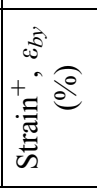 & $\frac{\overrightarrow{0}}{\omega \overrightarrow{0}}$ \\
\hline & \multicolumn{5}{|c|}{ 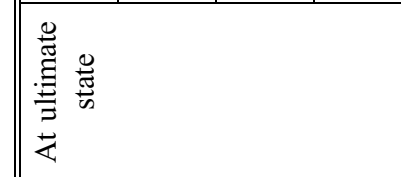 } & \multicolumn{2}{|l|}{ 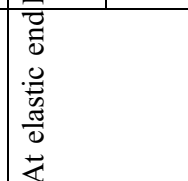 } & 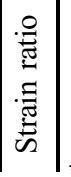 \\
\hline
\end{tabular}

International Journal of Concrete Structures and Materials (Vol.9, No.1, March 2015) | 25 


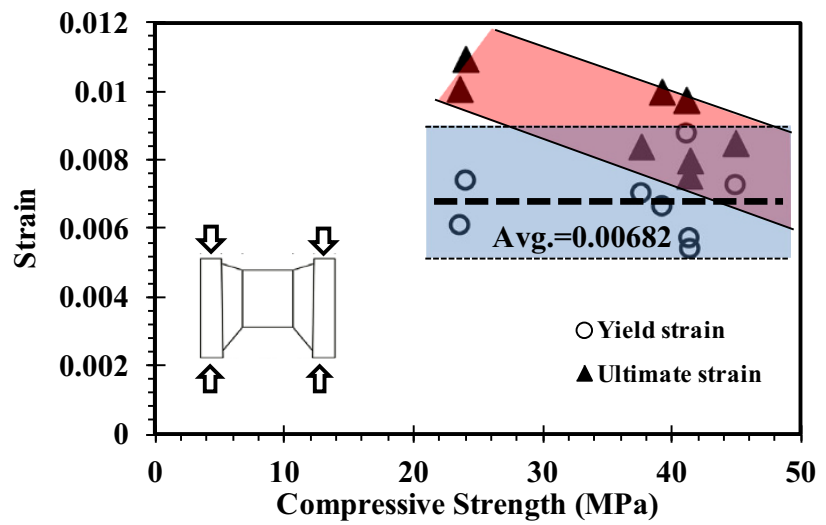

Fig. 5 Variation of strains corresponding to compressive strength of single form-blocks.

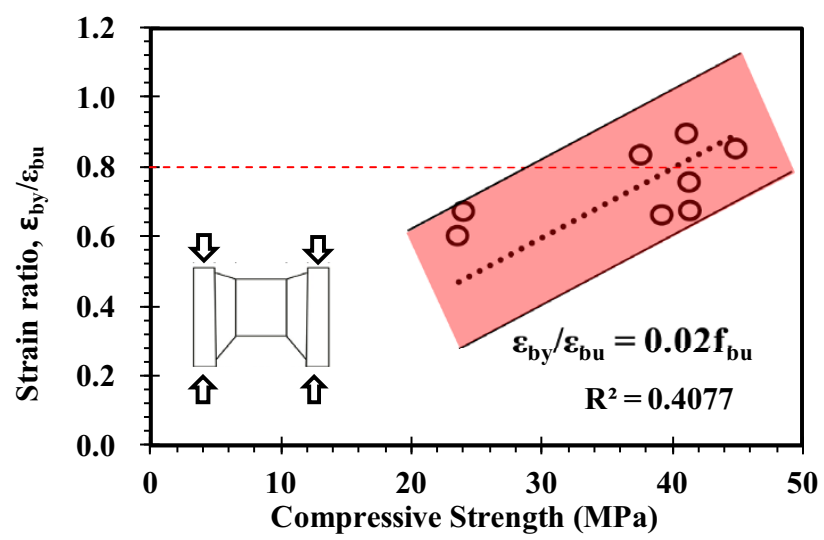

Fig. 6 Relationship between strain ratio and compressive strength in single form-block.

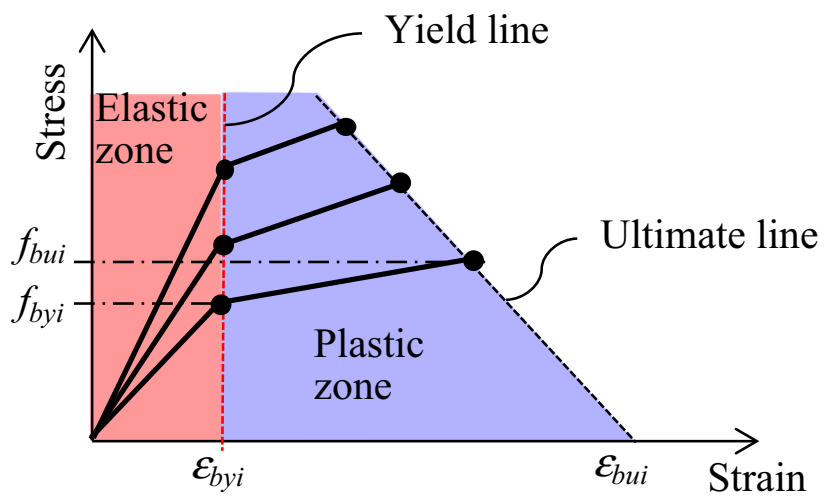

Fig. 7 Variations of yield and ultimate lines corresponding to the ultimate strength of block.

strain without considering the compression strength change of the block was about $80 \%$ of the strain at ultimate strength. Considering such a result, the stress-strain relation of the form block can be expressed in a bi-linear model, as shown in Fig. 8.

\section{Prism Test}

\subsection{Overview and Method}

To determine the compression strength of the block filled with grouted concrete, the prism test was conducted, where

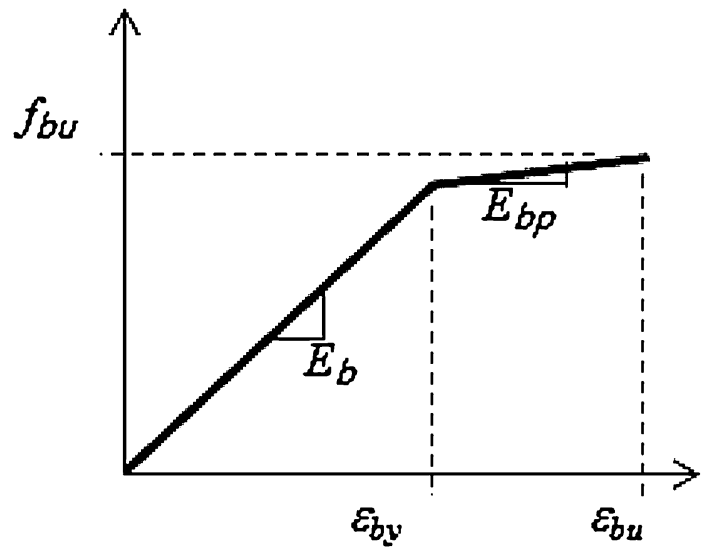

Fig. 8 Idealized bi-linear stress-strain model of form-block.

there were every three prism specimens for a total of eight parameters (two grouted concrete parameters and four single block parameters; total of 24 specimens). Shown in Table 3 are the dimension of the specimens, the compression strength of the single form block, and the material test strength of the grouted concrete and bearing mortar. Referring to KBC 2009 Prism Construction and Test (2009), the single block was cut in halves, as shown in Photo 1, and the blocks were stacked by three with the layering mortar, based on a $10 \mathrm{~mm}$ continuous joint thickness. Then concrete was poured inside the hollow zone attached with the form on the side to create prism specimens. After 20-day curing, compression force was applied on the specimens, using the Universal Testing Machine. To prevent specimen eccentricity, the compression force was applied to the specimens after attaching steel plates horizontally on the top and bottom of the specimens, using gypsum.

As shown in Fig. 9, the displacement was measured using the LVDT (linear variable differential transformer) installed in four corners, and a $60 \mathrm{~mm}$ concrete strain gauge was attached perpendicularly to the four central parts of the specimen to measure the strain on the initial elastic zone. The displacement gauge was used to measure the overall compression strain based on the increase in compression force, and the concrete strain gauge was used to observe the stress from the amount of compression strain, which was generated at the block flange and grouted concrete.

\subsection{Prism Test Result}

\subsubsection{Load-Displacement Curve}

Shown in Fig. 10 is the load-displacement curve that illustrates the effect of the block strength by the compression strength of grout concrete. If the strength of grout concrete is identical and the block strength differs, the larger the block strength is, the larger the prism strength becomes. This difference was shown to be larger with low grout concrete strength. In particular, in the case of the initial stiffness on the load-displacement curve, the stiffness change based on the block strength was found to be large for grout concrete with low strength whereas it was even regardless of the block strength if the grout concrete had high strength. This shows that if the strength of grout concrete is similar to or 
Table 3 Dimension and material strengths of prism test specimens.

\begin{tabular}{c|c|c|c}
\hline Specimen name & $\begin{array}{c}\text { Width } \times \text { length } \times \text { height } \\
(\mathrm{mm} \times \mathrm{mm} \times \mathrm{mm})\end{array}$ & $f_{\text {bu }}$ (Mpa) & $f_{g}$ (Mpa) \\
\hline \hline B1-C1 & $200 \times 208 \times 580$ & 23.27 & 36.3 \\
\hline B1-C2 & $200 \times 208 \times 582$ & 23.27 & 19.7 \\
\hline B2-C1 & $200 \times 207 \times 584$ & 39.45 & 36.3 \\
\hline B2-C2 & $200 \times 208 \times 584$ & 40.13 & 19.7 \\
\hline B3-C1 & $200 \times 209 \times 581$ & 40.13 & 36.3 \\
\hline B3-C2 & $200 \times 209 \times 578$ & 43.06 & 19.7 \\
\hline B4-C1 & $200 \times 208 \times 580$ & 43.06 & 36.3 \\
\hline
\end{tabular}

$f_{b u}$ and $f_{g}$ are compressive strength of block and grout concrete, respectively.

Bearing strength of mortar is 18.6 Mpa.

$B$ Mixed property, $C$ Compressive strength of grout concrete.

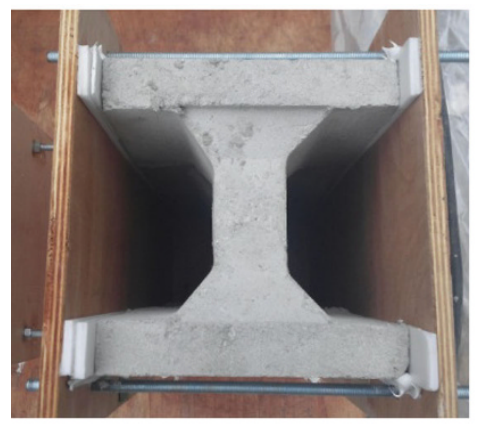

(a) Before grouting

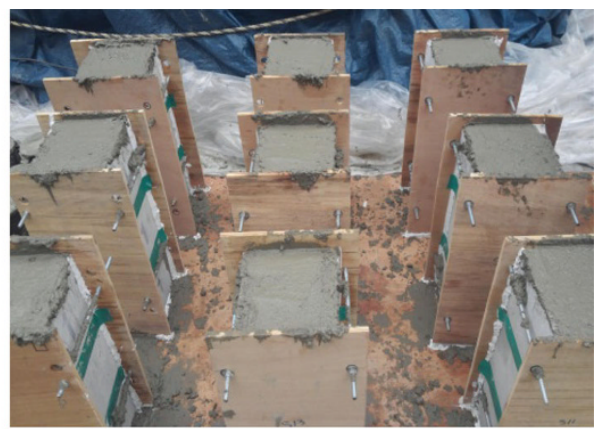

(b) After grouting

Photo 1 Manufacturing specimens for prism test.

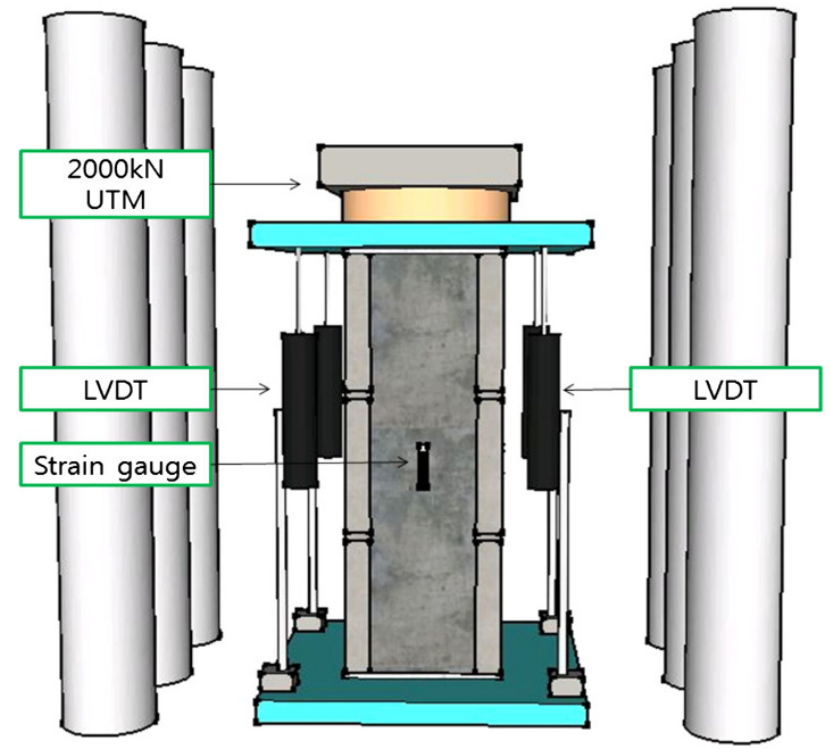

Fig. 9 Setup of prism test.

lower than the strength of the block, the block strength determines the prism strength, but if it is considerably higher than the block strength, the strength of grout concrete determines the prism strength. Figures 11 and 12 show the load variation corresponding to the strength of block and grout concrete, respectively. As mentioned above, the strength variation due to the change of block strength is large in the case of high strength of grout.

\subsubsection{Strain and Failure Shape}

The strain gauge, which was installed to determine the stress flow between the block and grout concrete against the gradually increasing compression stress, showed that stress was relatively evenly delivered to the block and grout concrete. Figure 13 shows graphs of representative specimens, which show the stresses resulting from the strain gauges, which were attached perpendicularly onto the center surface of the block and grout concrete, and the applied force divided by the total area. The strain pattern based on the stress of the strain gauge attached onto the surface of the block flange and grout concrete showed that the strain was low on the block while the stress was low, but the amounts of strain were similar to each other in the end. In a construction project where the form block is used, the surface of grout concrete is not exposed outside and is constrained so that there would be a constraint effect until the failure of the block flange wall.

At the end of the process, the tensile force on the block web due to the horizontal expansion of the grout concrete poured into the hollow zone of the block as well as the 


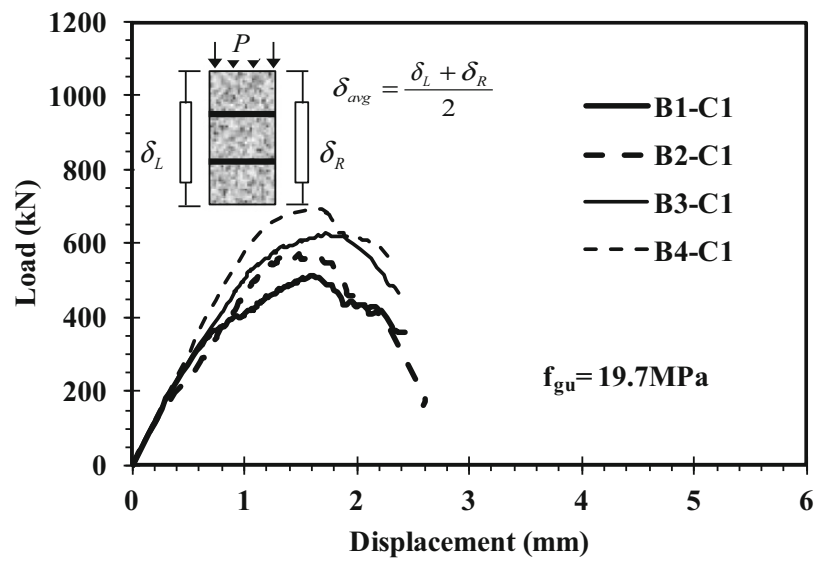

(a) Grout concrete strength $=19.7 \mathrm{Mpa}$

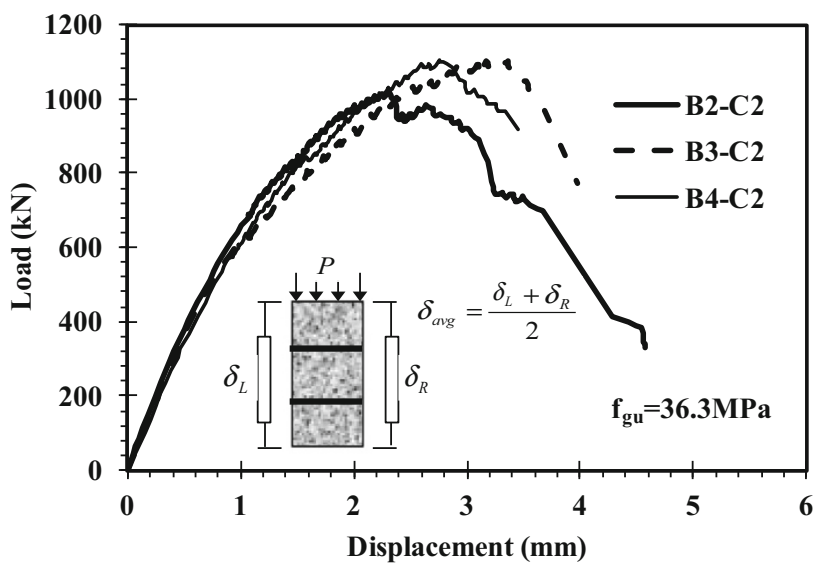

(b) Grout concrete strength $=36.6 \mathrm{Mpa}$

Fig. 10 Load-displacement curve corresponding to compressive strength of grout concrete.

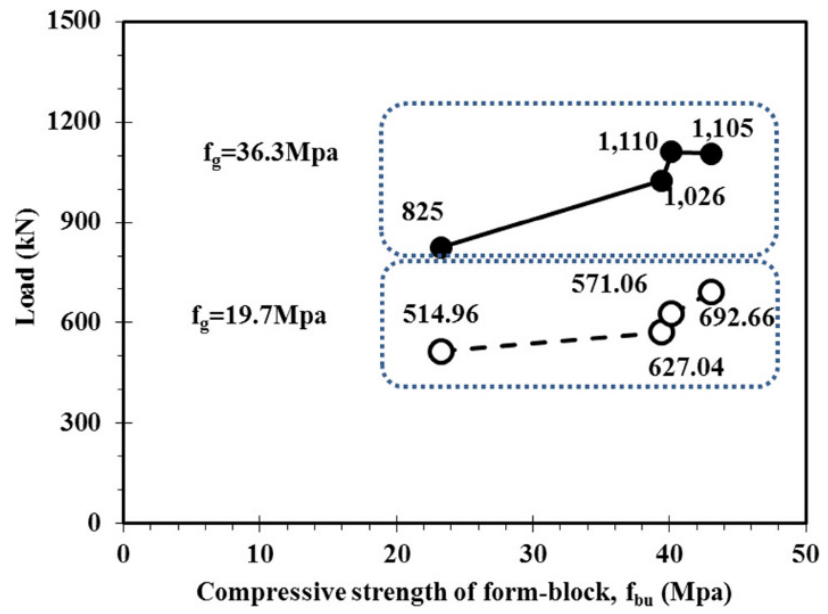

Fig. 11 Load variation due to compression strength of formblock.

compression displacement caused by the increased force resulted in the failure of the side flange of the form block. Shown in Photo 2 and Fig. 14 are the typical final failure and the failure behavior of the prism compression-strength specimens. There were few failures on the block flange whereas horizontal fractures were shown on the side of the grouted concrete. Also, as has been mentioned, the final

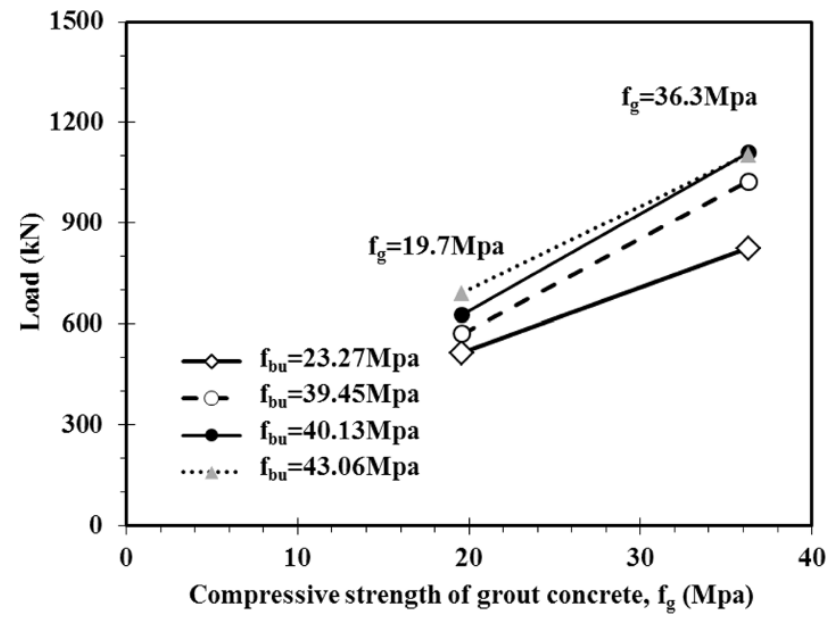

Fig. 12 Load variation due to compressive strength of grout concrete.

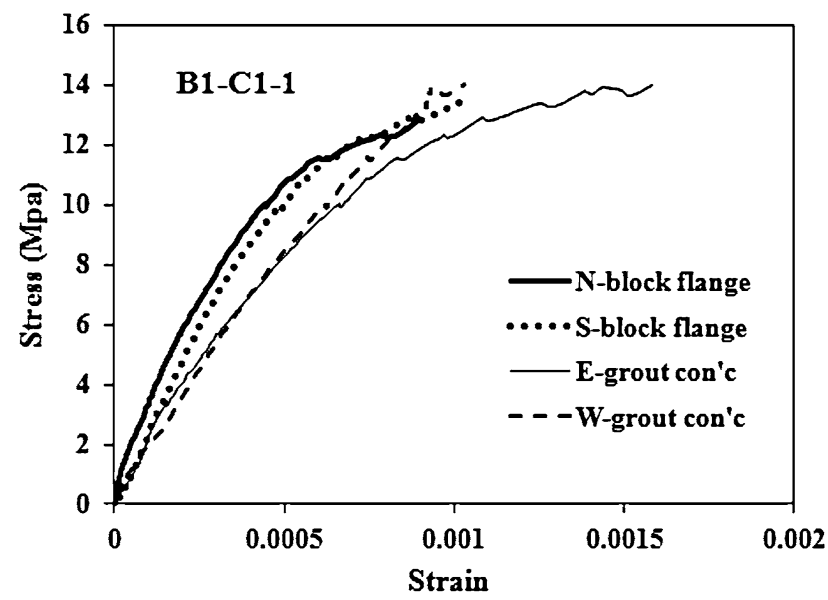

(a) Block

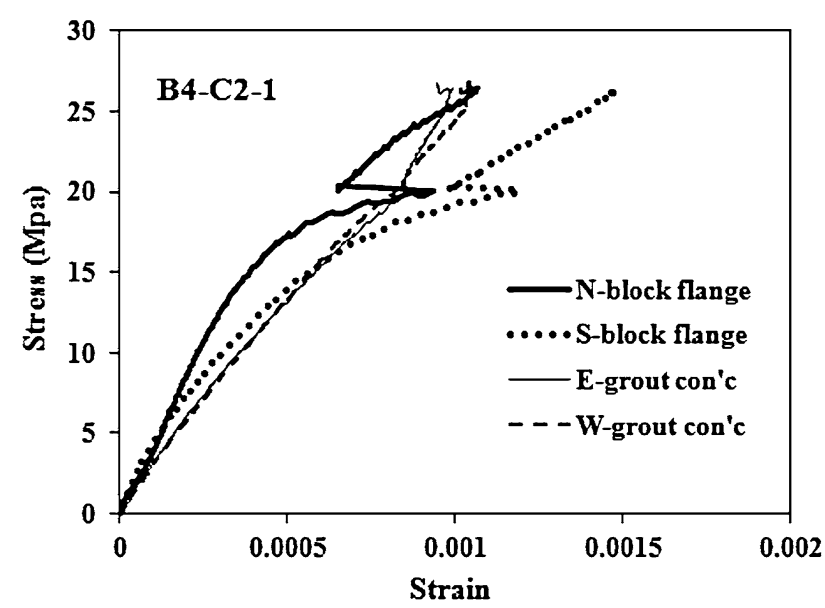

(b) Grout concrete

Fig. 13 Stress-strain curve of block and grout concrete.

failure occurred as the flange was detached due to the failure of the block web shear.

\subsubsection{Compression Strength Evaluation of the Form Block}

In relation to calculating the compression strength of the form block, Architectural Institute of Japan Code (2006) 


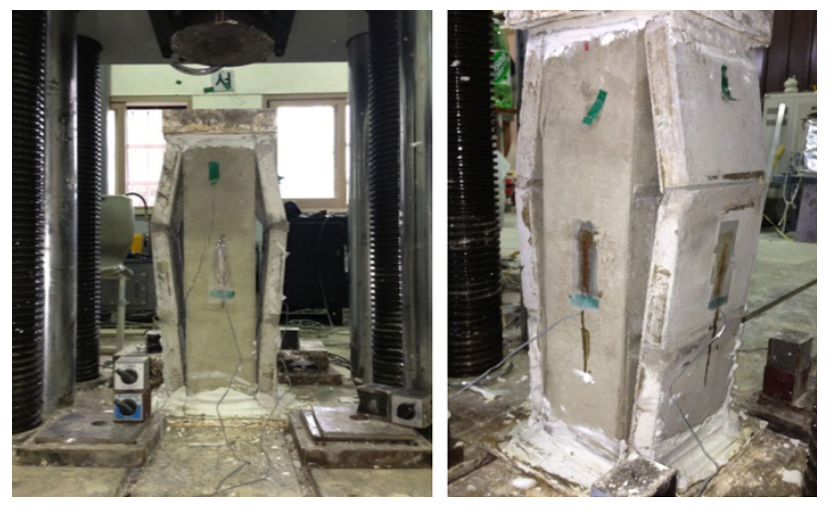

Photo 2 Typical failure shape of block wall after prism test (B3-C1-1)

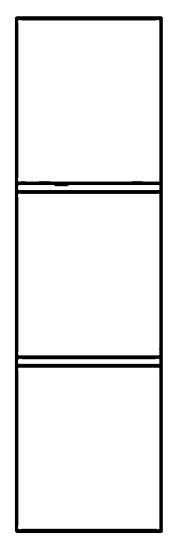

$\mathrm{N}$

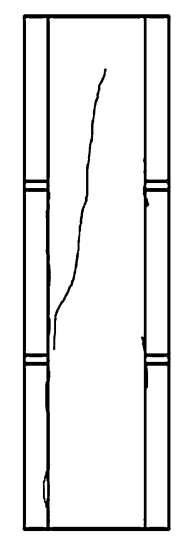

E

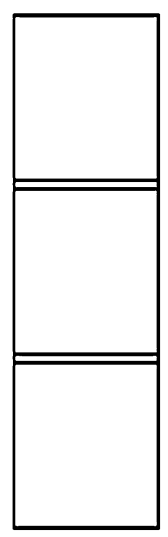

$S$

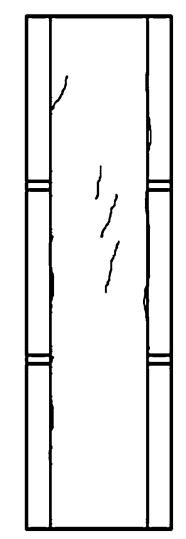

W
Fig. 14 Typical final crack shape of block wall after prism test (B3-C1-1).

defines, in their wall-structure design standard, the fourweek compression strength through the test on the walls as the design strength, which can be calculated using Eq. (1) if there is sufficient information on the materials constituting the masonry walls. This equation is used to calculate the

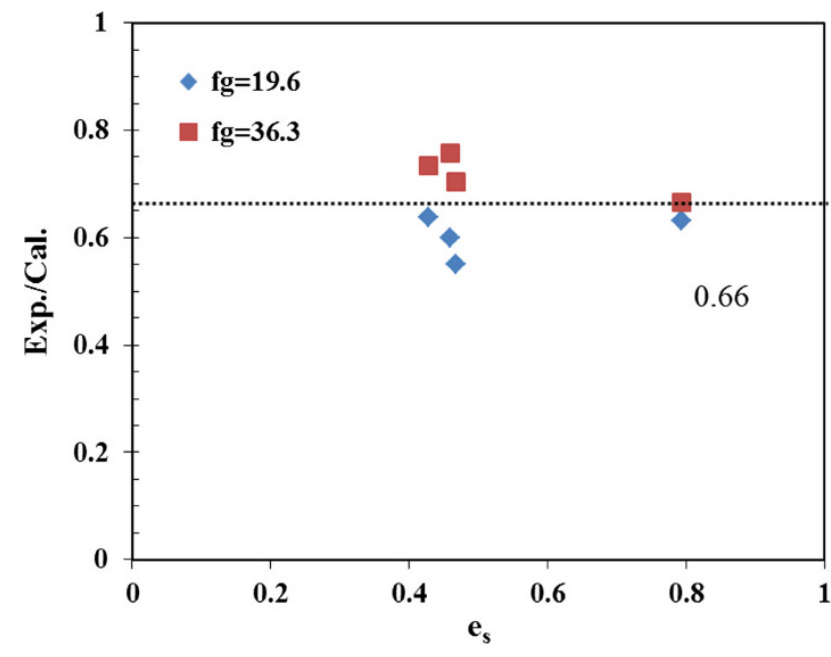

Fig. 15 Variation of ratios between test and calculation results corresponding to mortar factor.

compression strength of the new form block, where the strength of the grout concrete and that of the block parts are simply added up to produce the prism strength. Also, by implementing the mortar coefficient, the strength is reduced based on the ratio of the bearing mortar strength to the block strength if the former is lower than the latter. The suggested usual value, however, is 0.75 .

$$
F_{m}=e_{s}\left[\left(1-\beta^{\prime}\right) F_{u}+\beta^{\prime} F_{g}\right]
$$

where $e_{S}$ is mortar factor, ration between strength of bearing mortar and block strength, $F_{u}$ : strength of form-block (Mpa), $F_{g}$ : grout concrete strength $(\mathrm{Mpa}), \beta^{\prime}$ : volumetric hollow ratio, and $F_{m}$ : prism strength (Mpa).

Table 4 and Fig. 15 show the results of the calculation of the prism compression strength using Eq. (1), and of comparing the calculation result to the test result. The volumetric porosity of the form block was $65 \%$, and the strength of the form block and grout concrete was calculated based on the

Table 4 Comparison of prism test and calculation result.

\begin{tabular}{c|c|c|c|c|c|c|c}
\hline \multirow{2}{*}{ Specimen name } & \multicolumn{2}{|c|}{ Test result } & Mortar factor $e_{s}$ & $F_{m, c 1}(\mathrm{MPa})$ & $F_{m, c 2}(\mathrm{MPa})$ & $\frac{F_{m, \text { exp }}}{F_{m, c 1}}$ & $\frac{F_{m, \text { exp }}}{F_{m, c 2}}$ \\
\cline { 2 - 8 } & $\begin{array}{c}\text { Ultimate load } \\
(\mathrm{kN})\end{array}$ & $\begin{array}{c}\text { Ultimate strength } \\
F_{m, \text { exp }}(\mathrm{MPa})\end{array}$ & & & & & 0.63 \\
\hline \hline B1-C1 & 514.96 & 13.20 & 0.79 & 20.88 & 11.49 & 1.15 \\
\hline B2-C1 & 571.06 & 14.64 & 0.47 & 26.55 & 14.60 & 0.55 & 1.00 \\
\hline B3-C1 & 627.04 & 16.08 & 0.46 & 26.79 & 14.73 & 0.60 & 1.09 \\
\hline B4-C1 & 692.66 & 17.76 & 0.43 & 27.81 & 15.30 & 0.64 & 1.16 \\
\hline B1-C2 & 824.58 & $21.14-$ & 0.79 & 31.74 & 17.46 & 0.67 & 1.21 \\
\hline B2-C2 & 1025.5 & 26.29 & 0.47 & 37.40 & 20.57 & 0.70 & 1.28 \\
\hline B3-C2 & 1110.32 & 28.47 & 0.46 & 37.64 & 20.70 & 0.76 & 1.38 \\
\hline B4-C3 & 1105.1 & 28.34 & 0.43 & 38.67 & 21.27 & 0.73 & 1.33 \\
\hline Avg. & & & & & & 0.66 & 1.20 \\
\hline
\end{tabular}




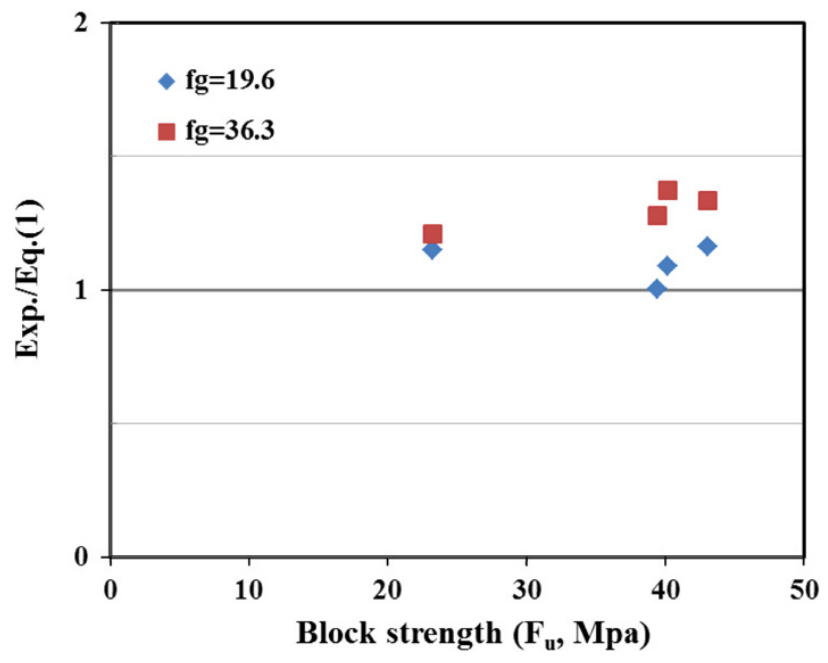

Fig. 16 Comparison of test and calculation results after applying new average mortar factor.

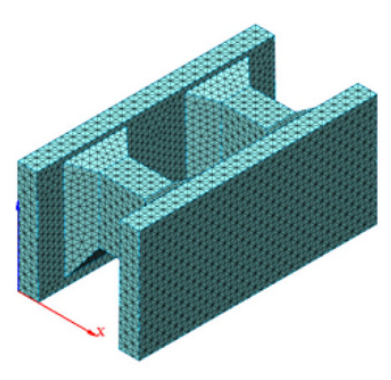

(a) Form-Block

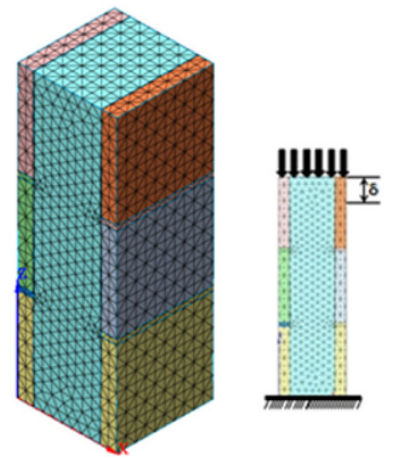

(b) Prism test
Fig. 17 Modeling for finite element analysis.

material test results. In this study, the strength of the bearing mortar was constant while the block strength changed so that the aforementioned mortar factor changed. As the mortar coefficient which is horizontal axis changed from 0.46 to 0.79 , there was no difference in the strength ratio. This means that the mortar coefficient does not change based on the strength change of the bearing mortar or block, and is determined by the lower strength of the two. If the mortar coefficient is not considered, the ratio of the test result to the calculation was 0.66 on average, but the average strength of the B2-C1 specimen group was extremely low. As such, 0.66 was discarded, and 0.55 was used instead as the mortar coefficient to calculate the strength. The result of the calculation is shown in Fig. 16. Overall, the figure shows that the calculation result predicted the test result appropriately and conservatively.

\section{Analysis of Compression Behavior Using Finite Element Analysis}

\subsection{Overview and Modeling}

In this study, to analyze the compression-failure behavior of the single form block and prism specimens, nonlinear finite element analyses of the single form block in Fig. 17a and of the prism specimens in Fig. 17b were conducted by using Midas FEA program (2013). The compression material block model that was used in the analyses was a $3 \mathrm{D}$ solid element. The material model presented was used as the result of the compression test of the single form block, and its properties were based on the material test results. Shown in Fig. 18 are the tensile and compression material models of grout concrete and mortar, where the tensile strength was set to $1 / 10$ of the compression strength.

The crack model of the prism specimens was the total strain crack model, which was used with the consideration of concrete cracks. In this analysis, the total strain crack model of the discrete crack model was used. And fixed crack model was applied.

To compare the parameters with the test results, the failure behavior was analyzed while considering the interfacial condition between the materials and the same strength of the form block and grout concrete as the test parameters. The interfacial condition model used two methods: the weld contact and the general contact. The weld contact method is used when the main and subsequent contact areas are attached to one another from the initial stage; it does not

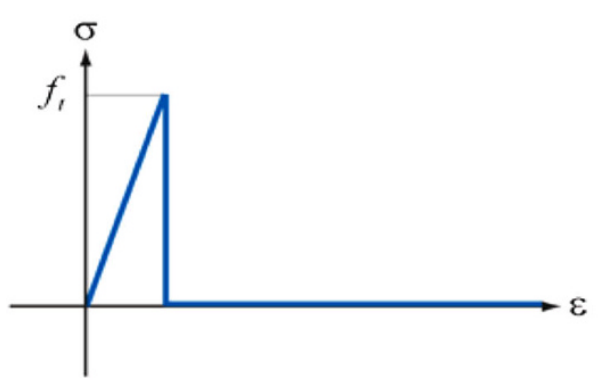

(a) Stress-strain of tension (Brittle)

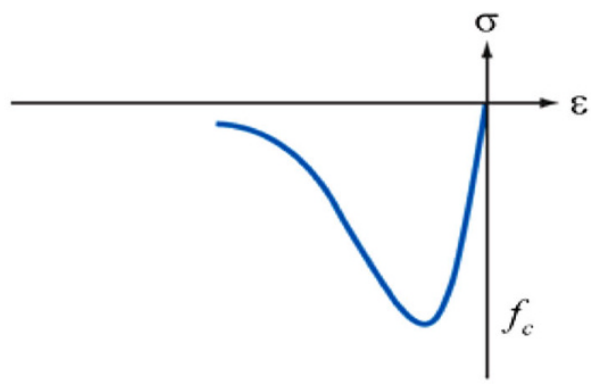

(b) Stress-strain of compression

(Thorenfeldt)

Fig. 18 Material model of grout concrete and mortar. 


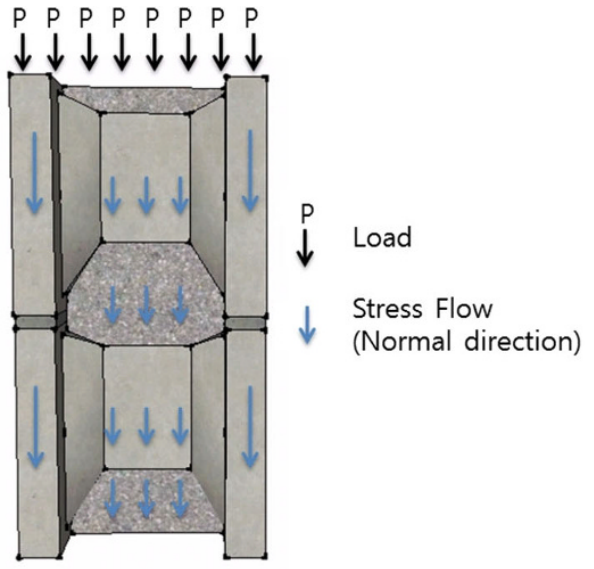

(a) General Contact

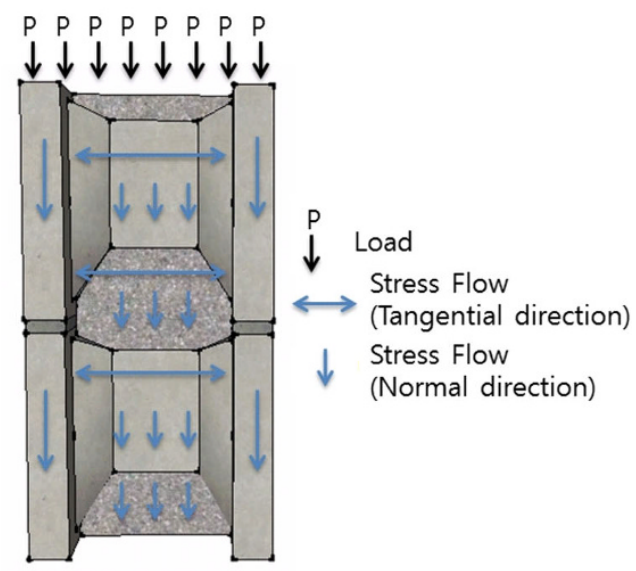

(b) Weld Contact

Fig. 19 Conceptual diagram of stress flow.

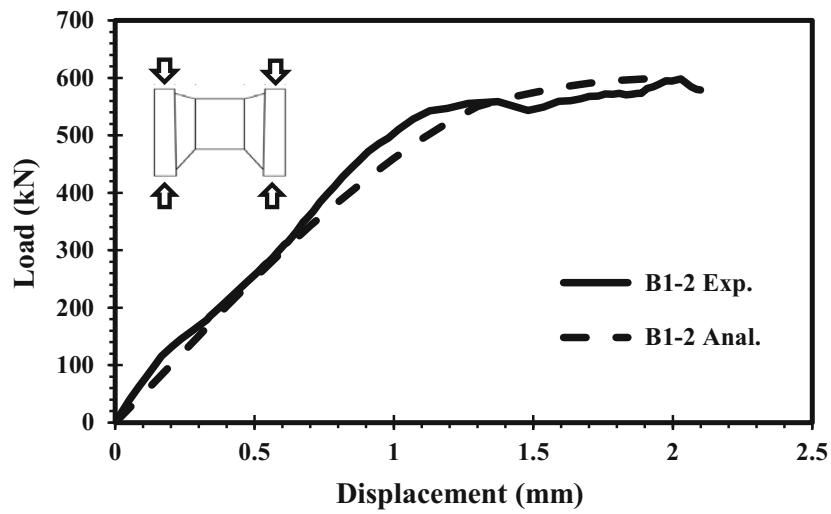

(a) B1 series

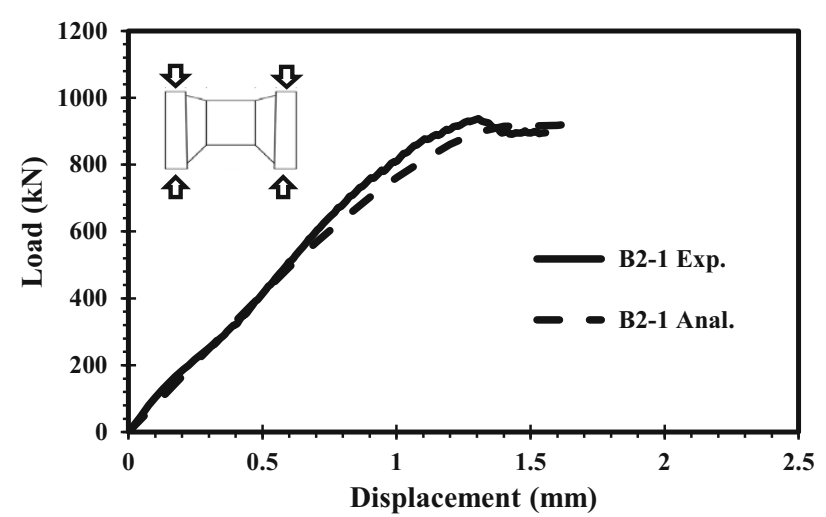

(b) B2 series

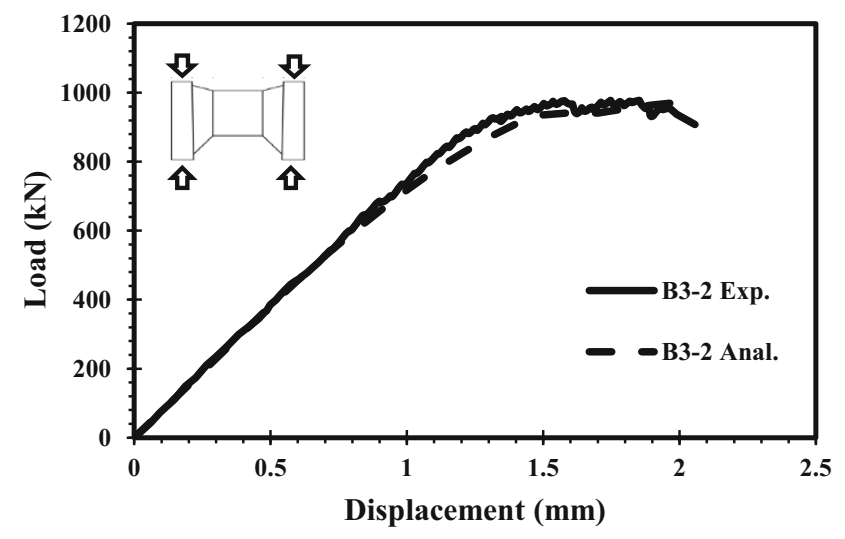

(c) B3 series

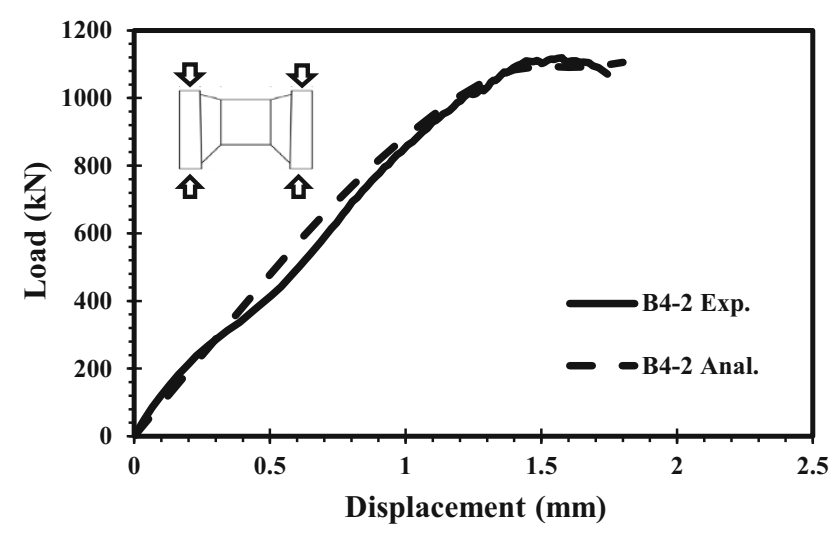

(d) B4 series

Fig. 20 Comparison of FE analysis and test results for single block walls.

allow the two surfaces to be detached during the analysis so that the load is delivered in the direction of the normal and contact directions of the model. The general contact method is used when the two surfaces were attached before the analysis and detached during the analysis as well as when the two surfaces continue to be attached and detached. The load is delivered only to the normal direction as shown in Fig. 19.

\subsection{Analysis Result of the Single Form Blocks}

Shown in Fig. 20 is the single form block analysis result, which was shown in the load-displacement curve by comparing it to the test result. The block compression-material model used the bi-linear model in Fig. 8, which was based on the single form block test result. The analysis result showed that the load-displacement curve pattern, the maximum load, the initial stiffness, etc. of the test results were 
appropriately demonstrated so that it was determined that the block behavior could be explained by using the bi-linear model in Fig. 8.

\subsection{Analysis Result of the Prism Specimens}

Figure 21 shows the flow of the force at the maximum load, which demonstrates that together with the compression displacement caused by the increase in the working load, the tensile force on the block web due to the horizontal expansion of the grout concrete poured into the hollow zone of the
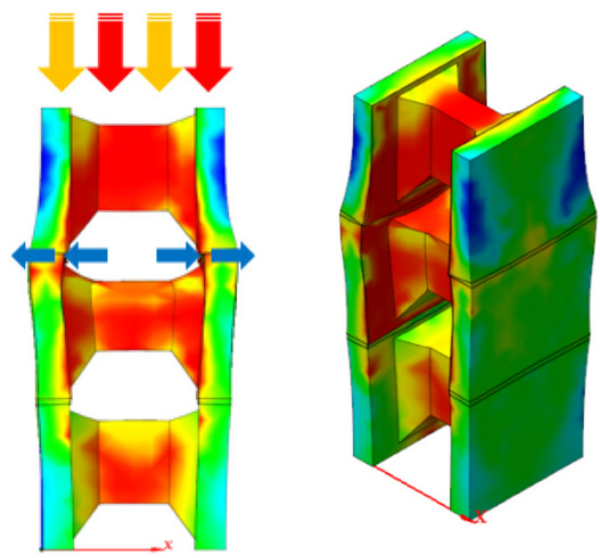

Fig. 21 Stress flow and deformation shape of prism test specimen at ultimate strength.

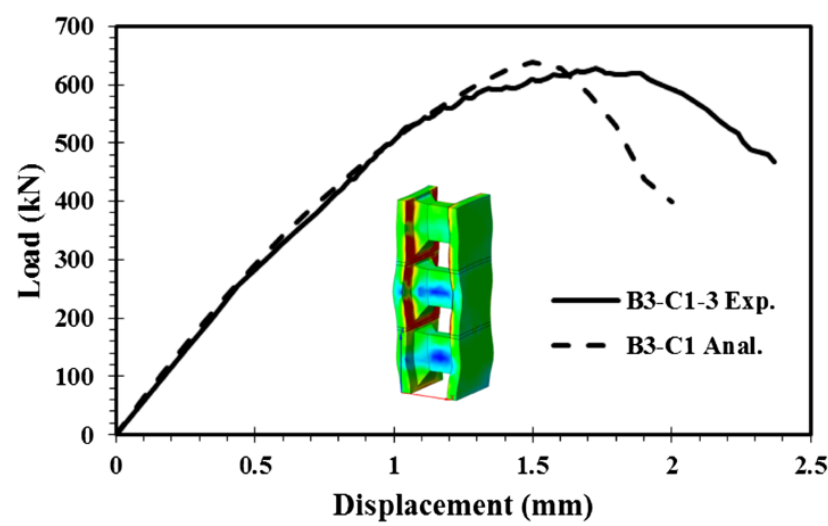

(a) B3-C1 series

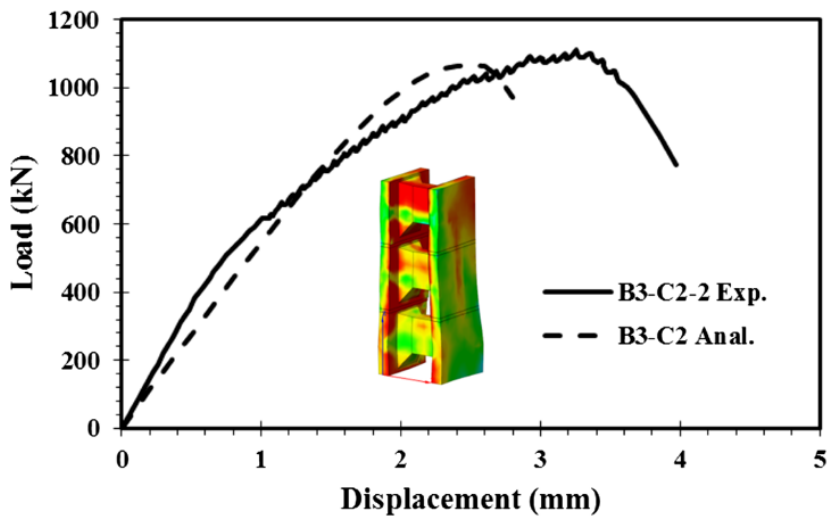

(b) B3-C2 series block resulted in the failure of the specimens where the lateral flanges of the form block failed. The general and subsequent contacts, used as parameters, showed the same failure behavior so that the stress delivered by the contact direction had little effect on the specimens, and the stress on the normal direction determined the compression behavior.

Shown in Fig. 22a and b are the load-displacement curves of the prism specimens (B3 series) compared with the test results, and shown in Fig. 22c and d are those of the prism specimens (B4 series) compared with the test results. While the analysis result of the strength of prism specimens was similar to the test result, even if the strain at the maximum strength was little bit smaller than the test result.

\section{Conclusions}

(1) From the single form block, all the specimens showed bi-linear load-displacement relation. The strain ratio of the elastic limit to the strain at maximum strength increased according to the maximum compression strength of material. It reaches $2 \%$ of the maximum compression strength of the block, and the total average value without considering the compression strength change of the block was about $80 \%$ of the strain when the strain at the elastic limit was at the maximum strength.

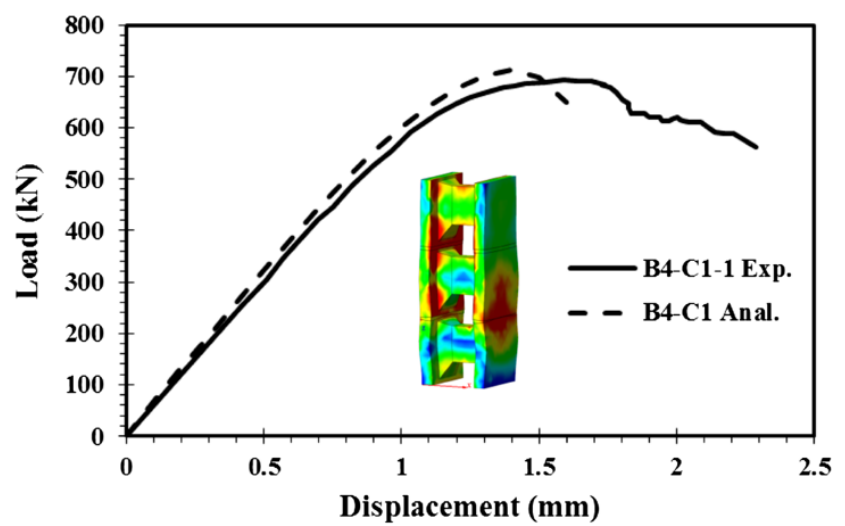

(c) B4-C1 series

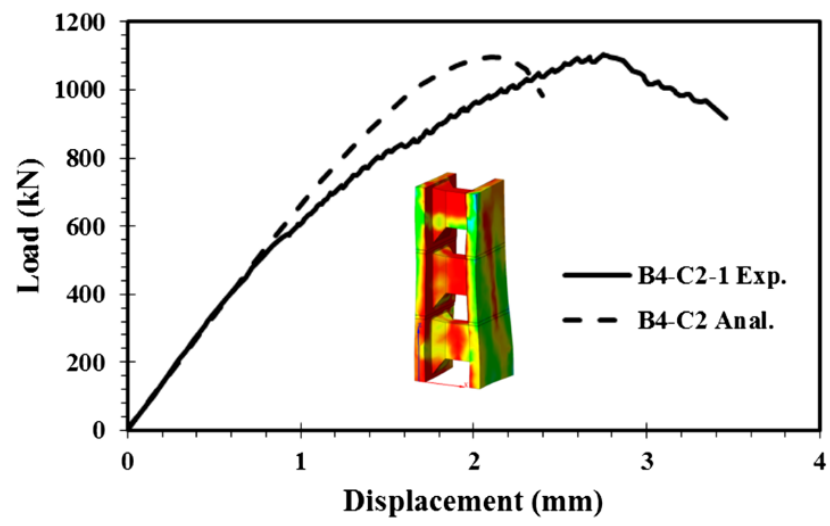

(d) B4-C2 series

Fig. 22 Comparison of FE analysis and test result of prism specimens. 
(2) The prism test result showed that when the grout concrete strength was lower than or similar to the strength of the block, the block strength governed the prism strength. When the strength of the grout concrete was considerably higher than that of the block, however, the grout concrete strength governed the prism strength. In the case of the failure shape, due to the compression deformation generated by the load increment as well as the tensile force on the block web due to the horizontal expansion of the grouted concrete poured into the hollow zone of the block, the lateral flanges of the form block failed.

(3) The comparison of the strength equation from Architectural Institute of Japan to the prism compression test shows that the mortar coefficient is not variable value. If 0.75 , which is usually implemented in the Japanese wall structure design standard, is used, the strength of the specimens is over evaluated by about $12 \%$. In this study, based on the test result, 0.55 was used as the mortar coefficient for safe design purpose. The calculation result based on this mortar coefficient was compatible with the test result.

(4) Based on the compression test result of the single form block, the stress-strain relation of the block is proposed as a bi-linear model. The finite element analysis result using the proposed model showed that the stress flow and the load-displacement curve were very similar to those of the test result. Also, using the proposed model, finite element analysis was conducted on the prism specimens, and it was shown that the proposed model predicted the compression behavior of the form block appropriately.

\section{Acknowledgments}

The authors acknowledge the support provided by Korea Association of Industry, Academy, and Research Institute (KAIARI) as one of the 2012 international business cooperation and technology development projects.

\section{Open Access}

This article is distributed under the terms of the Creative Commons Attribution License which permits any use, distribution, and reproduction in any medium, provided the original author(s) and the source are credited.

\section{References}

Architecture Institute of Japan (2006). Standards for structural design of masonry structures.

Jonaitis, B., \& Zavalis, R. (2013). Experimental research of hollow concrete block masonry stress deformations. Procedia Engineering, 57, 473-478.

KS F 4002 (2011). Hollow concrete block.

Kim, K.-T., Seo, S.-Y., Yoon, S.-J., Yoshimura, K., \& Sung, K.T. (2004). Experimental study for higher seismic performance of confined masonry wall system, Korea Concrete Institute, (Vol.12(1), pp. 3-8) Proceeding of Fall Conference, November.

Ministry of Construction and Transportation. (2013). Korean architectural standard specification, pp. 7-53-7-55.

Ministry of Land, Transport and Maritime Affairs (2009). KBC 2009, Production and Experiment of Prism, 2009-1245, 0603.4.6.

Shing, P. B., Noland, J. L., Klamerus, E., \& Spaeh, H. (1989). Inelastic behavior of concrete masonry shear wall. Journal of Structural Engineering ASCE, 115(9), 2204-2225.

Yun, H.-D., Han, M.-K., Kim, S.-W., Lee, G.-W., Park, W.-S., \& Choi, C.-S. (2005). Structural performance of lightly reinforced concrete frame strengthened with infilled walls by concrete blocks made in recycled sands. Journal of the Architectural Institute of Korea, 21(4), 83-90.

Zhai, X., \& Stewart, M. G. (2010). Structural reliability analysis of reinforced grouted concrete block masonry walls in compression. Engineering Structures, 32(1), 106-114. 